PREPARED FOR THE U.S. DEPARTMENT OF ENERGY, UNDER CONTRACT DE-AC02-76CH03073

PPPL-3894

PPPL-3894

UC-70

Control System for the NSTX Lithium Pellet Injector

by

P. Sichta, J. Dong, R. Gernhardt,

G. Gettelfinger, and H. Kugel

October 2003

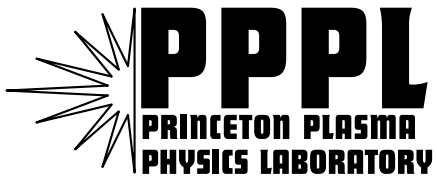

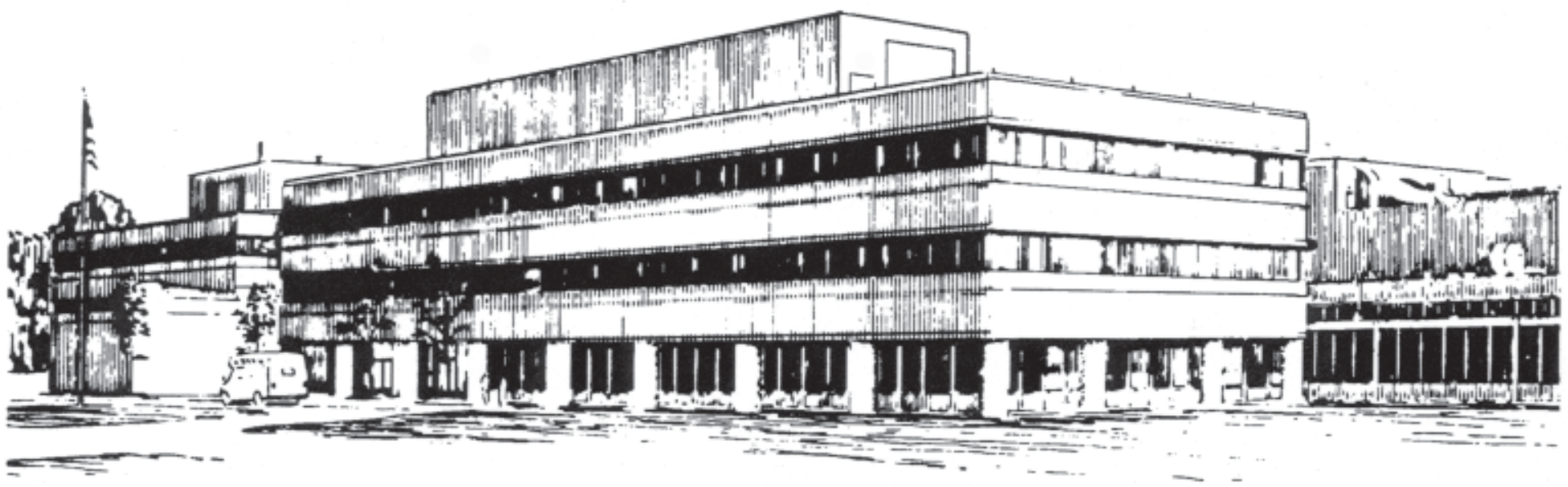

PRINCETON PLASMA PHYSICS LABORATORY PRINCETON UNIVERSITY, PRINCETON, NEW JERSEY 


\section{PPPL Reports Disclaimer}

This report was prepared as an account of work sponsored by an agency of the United States Government. Neither the United States Government nor any agency thereof, nor any of their employees, makes any warranty, express or implied, or assumes any legal liability or responsibility for the accuracy, completeness, or usefulness of any information, apparatus, product, or process disclosed, or represents that its use would not infringe privately owned rights. Reference herein to any specific commercial product, process, or service by trade name, trademark, manufacturer, or otherwise, does not necessarily constitute or imply its endorsement, recommendation, or favoring by the United States Government or any agency thereof. The views and opinions of authors expressed herein do not necessarily state or reflect those of the United States Government or any agency thereof.

\section{Availability}

This report is posted on the U.S. Department of Energy's Princeton Plasma Physics Laboratory Publications and Reports web site in Fiscal Year 2004. The home page for PPPL Reports and Publications is: http://www.pppl.gov/pub_report/

DOE and DOE Contractors can obtain copies of this report from:

U.S. Department of Energy

Office of Scientific and Technical Information

DOE Technical Information Services (DTIS)

P.O. Box 62

Oak Ridge, TN 37831

Telephone: (865) 576-8401

Fax: (865) 576-5728

Email: reports@adonis.osti.gov

This report is available to the general public from:

National Technical Information Service

U.S. Department of Commerce

5285 Port Royal Road

Springfield, VA 22161

Telephone: $1-800-553-6847$ or

(703) $605-6000$

Fax: (703) 321-8547

Internet: http://www.ntis.gov/ordering.htm 


\title{
Control System for the NSTX Lithium Pellet Injector *
}

\author{
P. Sichta, J. Dong, R. Gernhardt, G. Gettelfinger, H. Kugel \\ Princeton Plasma Physics Laboratory, P.O. Box 451, Princeton, New Jersey 08543
}

\begin{abstract}
The Lithium Pellet Injector (LPI) is being developed for the National Spherical Torus Experiment (NSTX). The LPI will inject 'pellets' of various composition into the plasma in order to study wall conditioning, edge impurity transport, liquid limiter simulations, and other areas of research. The control system for the NSTX LPI has incorporated widely used advanced technologies, such as LabVIEW ${ }^{\mathrm{TM}}$ and PCI bus I/O boards, to create a low-cost control system which is fully integrated into the NSTX computing environment. This paper will present the hardware and software design of the computer control system for the LPI.
\end{abstract}

\section{INTRODUCTION}

The National Spherical Torus Experiment (NSTX,) is evaluating the physics principles of spherical torus (ST) geometry [1]. An NSTX Lithium Pellet Injector (LPI) has been developed to inject 'pellets' of various composition into the plasma in order to study wall conditioning, edge impurity transport, liquid limiter simulations and other areas of ST research. The LPI project has presented an exciting opportunity to build a control system at NSTX that included advanced technologies. The vision for this system extended beyond designing an autonomous LPI control system. A primary goal of the design was to explore the recent advancements made by the NSTX Central Instrumentation and Controls group that address three key NSTX computing interfaces: network, data, and synchronization. Design considerations for the NSTX LPI control system included the following:

- Low-Cost

- Commercial Off The Shelf (COTS) parts

- Rapid development and test

- Minimize special designs

- Maintainability

- Use common components

- Avoid CAMAC

- Integration into the NSTX Computing and Controls Environment

- Create an architecture that is suitable as a 'template' for other systems and collaborators

The system is based on a rackmount PC using PCI input/output boards. The application software uses National Instruments ${ }^{\mathrm{TM}}$ LabVIEW, running on the Microsoft $\AA$ Windows $\AA$ operating system. LabVIEW was chosen because it offers direct support for a wide selection of PCI input/output boards. LabVIEW also has software interfaces to the two primary components of the NSTX computing environment, MDSplus [3] and EPICS [4]. Windows and LabVIEW provide a variety of solutions for remote access to the LPI computer.

\section{HARDWARE DESIGN}

A block diagram of the system is shown in Fig. 2 (see next page). The system's mechanical design includes eight launch barrels, a revolving 400-pellet magazine, and multiple valves for controlling the launch sequence [2]. The controls have been partitioned into three subsystems, Magazine Control, Launch Control, and Pellet Flight Telemetry.

\section{A. Magazine Control}

$\underline{\text { Key Features }}$

- 400-pellet revolving magazine

- 0.036 degrees radial accuracy

- Complete rotation in one minute

- Local controls to facilitate pellet loading

The revolving magazine is a circular assembly that has 400 tubes, 50 radial columns each with 8 axial rows. Each tube can be hand-loaded with a cartridge and its payload, a prefabricated pellet. The magazine is rotated to align with a fixed-position vertical array of 8 propellant barrels, as depicted in Fig. 1, below. The magazine's rotation is controlled using a 25:1 micro-step-controlled stepper motor, coupled to the magazine through a metal drive chain with a $6: 1$ gear ratio. A 5000 pulse-per-revolution encoder is coupled to the magazine assembly to keep track of the magazine's position.

The stepper motor and encoder are wired to a National Instruments Stepper Motor Driver and PCI Stepper Motor Controller board. Coupled with National Instruments-supplied

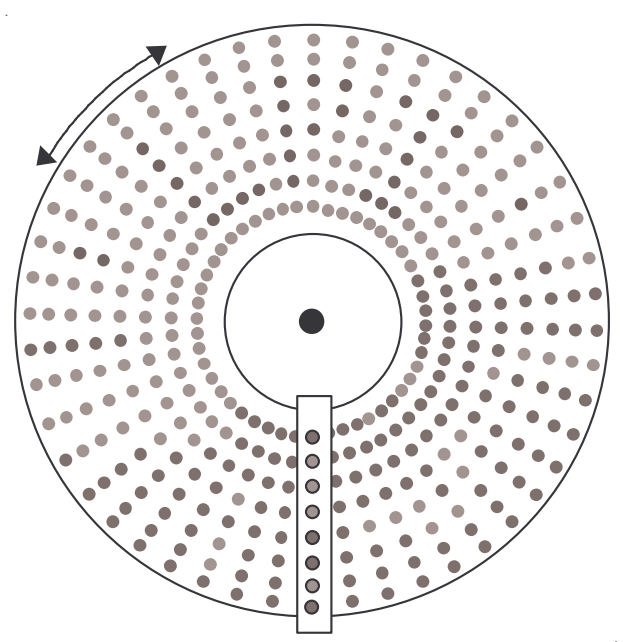

Fig. 1. Diagram of the 400-pellet magazine assembly and the launch barrel array. Dark and light dots indicate an empty or full magazine tube. 


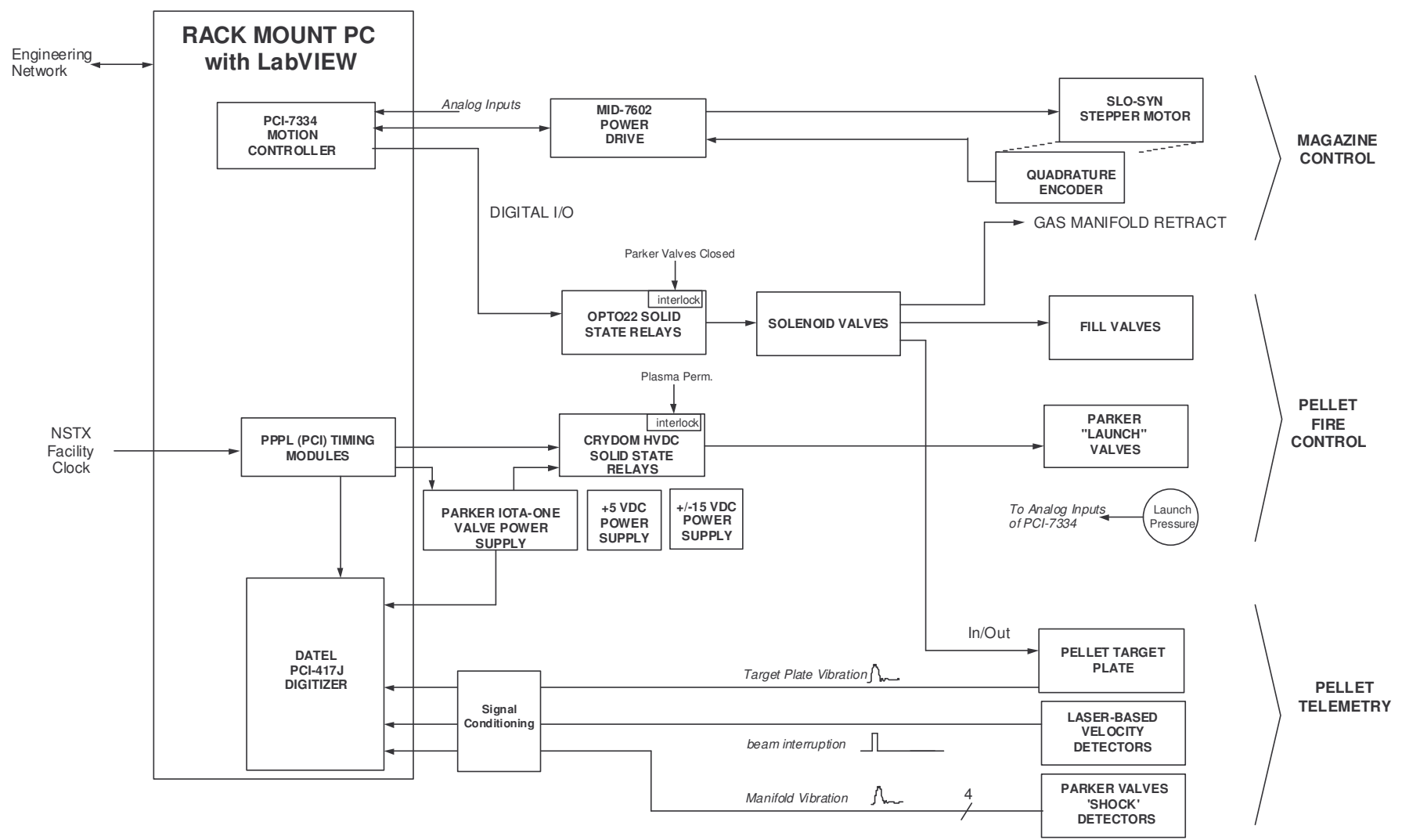

Fig. 2. Block Diagram of the LPI Control System Hardware

LabVIEW stepper motor software functions, this tightly integrated stepper motor control solution was virtually 'turnkey'.

\section{B. Launch Control}

\section{$\underline{\text { Key Features }}$}

- Independent timing and velocity for up to eight pellets per NSTX plasma-shot

- Fast hardware interlock inhibits launch of pellet in the absence of the plasma

- High voltage solid state relay switching network permits sharing of a single impulse-driven valve power supply

- Timing is preset, but hardware can support asynchronous launch triggers

Pellet Launch Control is the most complex of the three LPI subsystems. The configuration for each of the eight barrels include a fast-acting (200 microsecond) Parker-Hannifin ${ }^{\mathrm{TM}}$ Series 9 solenoid valve, a pressurized 'fill plenum', and a solenoid/pneumatic valve-set to pressurize the fill plenum prior to the launch. The Series 9 launch valves are solenoidoperated and can be affected by the magnetic fields near the NSTX vacuum vessel. The valves are encased in a mu-metal enclosure to prevent inadvertent valve operation.

The eight launch valves are driven from a single, ParkerHannifin model Iota-One power supply. This supply overdrives the launch valve with a 180 microsecond, 280 volt 'spike' at the rising edge of the control pulse, which is nominally $28 \mathrm{vdc}$. Before energizing the valve, however, the voltage must pass through two high voltage $(500 \mathrm{vdc})$ solid state relays (SSR). The first SSR is enabled by a (externallyderived) plasma permissive interlock. The second SSR is controlled by the PPPL PCI NSTX Timing system [5].

\section{1) PCI NSTX Timing System}

The PCI NSTX Timing system was designed at PPPL in order to have a CAMAC-free timing and synchronization system for NSTX diagnostics and other control applications. Each twoboard set provides six multifunction timing channels. One board resides in the control computer in a PCI bus slot. This is a commercially-produced board (CeSys ${ }^{\mathrm{TM}}$ model XC2S) that contains a Field Programmable Gate Array (FPGA). The FPGA has been loaded with a configuration that can decode NSTX Facility Clock events, such as $\mathrm{T}(0)$, provide timing delay functions, and then generate TTL timing signals. The TTL outputs are connected to an external (PPPL) circuit board located in a rack-mount electronics chassis. This board provides electrical isolation of the timing signals. The LPI is the first 'field' application of the new PCI Timing System.

Two (6-channel) PCI timing boards were required to support the eight launch valves, transient digitizer triggers, and other timing signals. 


\section{Pellet Flight Telemetry}

$\underline{\text { Key Features }}$

- Vibration sensors:

- Parker valve (solenoid) actuation

- Cartridge impact at end of magazine tube

- In-vacuum Target Plate pellet impact, used for test and calibration

- Optical sensor: Pellet exiting magazine tube

The LPI has sensors to detect that the launch sequence operated normally and also to provide information such as time of injection and pellet velocity. Several piezoelectric vibration sensors and one laser/optical detector are used. These signals are digitized using a Datel ${ }^{\circledR}$ model PCI-417J. This device has eight, 12-bit, simultaneous sampling ADCs, at rates up to $2.5 \mathrm{MHz}$. The digitizer streams the data across the PCI bus to system memory.

\section{SOFTWARE DESIGN}

The software is based upon LabVIEW, running on the Windows operating system.

\section{$\underline{\text { LabVIEW Key Features }}$}

- Popular and powerful programming environment, a de-facto standard for small control systems

- Driver and VI software support for PCI I/O boards supplied by board vendors

- Support for remote (program) control

- Free interface software for MDSplus and EPICS

- Software extensions for web browsers and databases

Like the hardware design, the software design was partitioned according to the LPI subsystem architecture, Magazine Control, Launch Control, and Launch Telemetry. Separate LabVIEW programs were written to serve each LPI subsystem, as depicted in Fig. 3. Each program can function autonomously to serve a subset of LPI functions, but for normal LPI operations all three programs are required.

To coordinate operations of the LPI, the three programs used LabVIEW's Global Variables to pass information. There are about fifteen global variables, such as watchdog counters, readiness permissives, launch-sequence state information, position information, NSTX shot number etc... LabVIEW's 'Tab' feature was used to permit a 'layered' display mechanism. The operator can use the mouse to poke the tab, and bring up a new display to the forefront. 10 displays (total) are used for the LPI.

The Pellet Launch program is also known as the 'main' program. For normal operations, the operator only needs to access this program's front panel. The main program can pass magazine-rotation requests to the Stepper Motor control program through the Global Variable space. Configuration displays to allow user to configure control software (override, MDSplus path, stepping rate, deadbands, etc...).

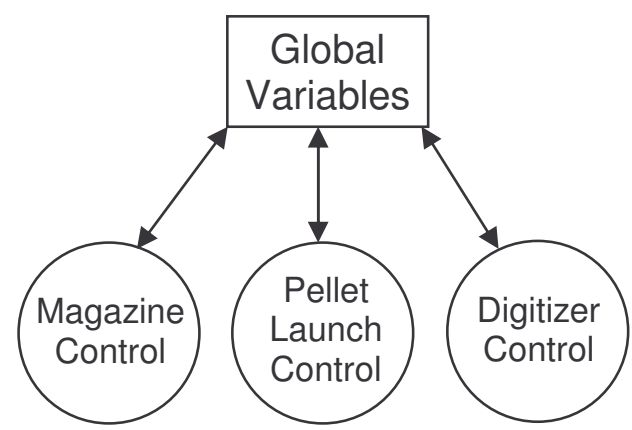

Fig. 3. Diagram depicts three LabVIEW programs on the same PC using Global Variables communicate.

\section{A. NSTX Computing Environment}

The NSTX Computing Environment [6] is built around two open-source, global-community software packages, MDSplus and EPICS. MDSplus is a set of software tools for data acquisition and storage and a methodology for management of complex scientific data. EPICS is a set of software tools, libraries and applications to create distributed soft real-time control systems. Both of these packages run on most popular operating systems and CPU architectures. The EPICS and MDSplus communities have provided interfaces for LabVIEW programs. The LPI software has included functions to read and write MDSplus and EPICS. These basic functions can be used to form the core of a template that can be used by (future) NSTX collaborator's who also use LabVIEW.

The MDSplus interface is used for saving shot-related data after each NSTX shot:

- Launch configuration: pressure, time, magazine location, etc...

- Injected-pellet characteristics: size, pellet ID, etc....

- Transient digitizer waveforms

- Program and hardware status information (word)

The EPICS interface is useful for automated operation:

- Shot time [e.g. T(-10)] to arm/disarm subsystems, run pre-shot checks, increase polling rates, etc...

- Detecting aborted shot cycles

- Post 'live' system status to EPICS database for centralized alarming

\section{B. Pellet Database}

A (LPI) Pellet Database is being planned. This database will contain records that track the life-cycle of each pellet and the current status of the 400-pellet cartridge tubes. Pellet characteristics will include items such as pellet ID, pellet mass, composition, manufacturing date, etc... The database will also record which magazine tube a pellet was loaded into, when it was injected or removed, shot number/date of injection, etc...

The database will be accessed by a variety of staff such as the pellet fabricator, the cartridge loader, the LabVIEW programs, the physicist running the NSTX experimental plan, and other researchers interested in pellet history. Note that the MDSplus shot data will include some of the items associated with the 
pellets (ID, composition, etc) that were launched into the plasma. The detailed design and access methods for the database will be deferred until some LPI operations experience has been gained.

\section{OPERATIONS}

The operating scenario for the LPI is to have the NSTX Vacuum Operator, under direction from the NSTX Physicistin-Charge, control and configure the LPI equipment from the NSTX Control Room. The LPI Operator will remotely access the LPI computer's 'desktop' using VNC [7]. The operator only needs to access one program window to pressurize the fill plenums, set timing, enable barrels, and rotate the magazine to the desired position. The planned Pellet Database will enhance the Physicist's ability to locate the desired pellets and streamline communication with the LPI/Vacuum Operator.

At the present time, the LPI software is started up manually using a procedure. In the future this process will be fully automated, so that when the PC is powered up all programs will start and the PCI Timing board's FPGA will automatically download its 'code'.

\section{CONCLUSION}

The LPI control system design and fabrication has been a success. The system's installation and commissioning in the NSTX Test Cell is expected to commence shortly. To reduce costs, component selection was made using free/open software, commercially-produced components, and lastly, PPPLengineered components. The partitioning of the control system into subsystems has encouraged modularization, such that the design of hardware and software was performed efficiently in a team environment.

The LPI software development proceeded very smoothly because of LabVIEW's rich and intuitive programming and testing environment. LabVIEW included high-level functions such as closed-loop motor position control, and the NI_MAX PCI module initialization and configuration utility. LabVIEW also provided a simple way to simulate values from non- present hardware and to-be-written software modules. This helped to accelerate software testing and will enhance integrated system testing

The basic architecture of the LPI control system can be used as a 'template' for other LabVIEW-based systems. Components such as the MDSplus interface, EPICS interface, and PCI NSTX Timing System can be used by other control systems to tightly integrate them into the NSTX computing and control environment.

\section{ACKNOWLEDGMENT}

This is work supported by U.S. DOE Contract DE-AC02$76 \mathrm{CH} 03073$.

\section{REFERENCES}

[1] J. E. Menard, et al., "Beta-limiting MHD Instabilities in Improved Performance NSTX Spherical Torus Plasmas", Nucl. Fusion, 43 (2003) 330 .

[2] G. Gettelfinger, et al., "Lithium Pellet Injector for NSTX," (this conf.) $20^{\text {th }}$ IEEE/NPSS Symposium on Fusion Engineering, San Diego, USA (2003).

[3] W. Davis, et al., "The use of MDSplus on NSTX at PPPL," $3^{\text {rd }}$ IAEA TCM on Control, Data Acquisition, and Remote Participation for Fusion Research, Padova, Italy (2001).

[4] P. Sichta, et al., "Status of the Experimental Physics and Industrial Control System at NSTX," $19^{\text {th }}$ IEEE/NPSS Symposium on Fusion Engineering, Atlantic City, USA (2002).

[5] P. Sichta, et al., "Developments to Supplant CAMAC Technology with Industry Standard Technology at NSTX," $4^{\text {th }}$ IAEA TCM on Control, Data Acquisition, and Remote Participation for Fusion Research, San Diego, USA (2003).

[6] P. Sichta, et al., "Overview of the NSTX Control System," $8^{\text {th }}$ International Conference on Accelerator and Large Experimental Physics Control Systems, San Jose, USA (2001).

[7] RealVNCTM Ltd., "Virtual Network Computing (VNC) Software Product," <URL: http: / / www.realvnc.com> [Accessed September, 2003]. 


\section{External Distribution}

Plasma Research Laboratory, Australian National University, Australia

Professor I.R. Jones, Flinders University, Australia

Professor João Canalle, Instituto de Fisica DEQ/IF - UERJ, Brazil

Mr. Gerson O. Ludwig, Instituto Nacional de Pesquisas, Brazil

Dr. P.H. Sakanaka, Instituto Fisica, Brazil

The Librarian, Culham Laboratory, England

Mrs. S.A. Hutchinson, JET Library, England

Professor M.N. Bussac, Ecole Polytechnique, France

Librarian, Max-Planck-Institut für Plasmaphysik, Germany

Jolan Moldvai, Reports Library, Hungarian Academy of Sciences, Central Research Institute for Physics, Hungary

Dr. P. Kaw, Institute for Plasma Research, India

Ms. P.J. Pathak, Librarian, Institute for Plasma Research, India

Ms. Clelia De Palo, Associazione EURATOM-ENEA, Italy

Dr. G. Grosso, Instituto di Fisica del Plasma, Italy

Librarian, Naka Fusion Research Establishment, JAERI, Japan

Library, Laboratory for Complex Energy Processes, Institute for Advanced Study, Kyoto University, Japan

Research Information Center, National Institute for Fusion Science, Japan

Dr. O. Mitarai, Kyushu Tokai University, Japan

Dr. Jiangang Li, Institute of Plasma Physics, Chinese Academy of Sciences, People's Republic of China

Professor Yuping Huo, School of Physical Science and Technology, People's Republic of China

Library, Academia Sinica, Institute of Plasma Physics, People's Republic of China

Librarian, Institute of Physics, Chinese Academy of Sciences, People's Republic of China

Dr. S. Mirnov, TRINITI, Troitsk, Russian Federation, Russia

Dr. V.S. Strelkov, Kurchatov Institute, Russian Federation, Russia

Professor Peter Lukac, Katedra Fyziky Plazmy MFF UK, Mlynska dolina F-2, Komenskeho Univerzita, SK-842 15 Bratislava, Slovakia

Dr. G.S. Lee, Korea Basic Science Institute, South Korea

Institute for Plasma Research, University of Maryland, USA

Librarian, Fusion Energy Division, Oak Ridge National Laboratory, USA

Librarian, Institute of Fusion Studies, University of Texas, USA

Librarian, Magnetic Fusion Program, Lawrence Livermore National Laboratory, USA

Library, General Atomics, USA

Plasma Physics Group, Fusion Energy Research Program, University of California at San Diego, USA

Plasma Physics Library, Columbia University, USA

Alkesh Punjabi, Center for Fusion Research and Training, Hampton University, USA

Dr. W.M. Stacey, Fusion Research Center, Georgia Institute of Technology, USA

Dr. John Willis, U.S. Department of Energy, Office of Fusion Energy Sciences, USA

Mr. Paul H. Wright, Indianapolis, Indiana, USA 
The Princeton Plasma Physics Laboratory is operated by Princeton University under contract with the U.S. Department of Energy.

\author{
Information Services \\ Princeton Plasma Physics Laboratory \\ P.O. Box 451 \\ Princeton, NJ 08543
}

Phone: 609-243-2750

Fax: 609-243-2751

e-mail: pppl_info@pppl.gov

Internet Address: http://www.pppl.gov 